\title{
CUADROS QUE SE PINTAN A SÍ MISMOS. FUNDAMENTOS DE UNA MITOLOGÍA DE LA RAZÓN EN NICOLÁS DE CUSA ${ }^{1}$
}

\author{
HARALD SCHWAETZER \\ Dr. en Filosofía \\ harald.schwaetzer@kueser-akademie.de \\ Hochschule Biberach - Biberach - Alemania \\ Kueser Akademie für Europäische Geistesgeschichte - Bernkastel-Kues - Alemania
}

Cómo citar este artículo:

H. Schwaetzer. (2020). "Cuadros que se pintan a sí mismos. Fundamentos de una mitología de la razón en Nicolás de Cusa” en Palabra y Razón. Revista de Teología, Filosofía y Ciencias de la Religión. No I8 Diciembre 2020, pp I22-I39 https://doi.org/IO.29035/pyr.I8.I22

I La presente contribución corresponde a la conferencia dictada en el Simposio de la Sociedad Cusana Japonesa con ocasión de la reunión anual 2018 en la Universidad Waseda de Tokio, por invitación del Presidente de la Sociedad el Prof. Dr. Kazuhiko Yamaki. Publicada por primera vez en alemán en: H. Schwaetzer, "Selbst malende Bilder. Grunzüge einer Mythologie der Vernunft bei Niolaus von Kues" en T. BORSCHE, H. SCHWAETZER (hgs.), Bilder beweglich denken. Akten des Symposions zu Ehren von Kazuhiko Yamaki, Aschendorf: Münster 2019, pp. 29-46. Traducción al español de Rodrigo Núñez, autorizada por el autor. 
"En primer lugar, hablaré aquí de una idea que, por lo que sé, aún no tiene ningún sentido humano - debemos tener una nueva mitología, pero esta mitología debe estar al servicio de las ideas, ella debe convertirse en una mitología de la razón".

Esta relación entre metafísica y mito como mitología de la razón se encuentra en el llamado Das älteste Systemprogramm des deutschen Idealismus (El más antiguo programa sistemático del idealismo alemán), el cual llegó a ser ampliamente recibido alrededor de I8oo por Friedrich Schlegel o Friedrich von Hardenberg, entre otros. El autor o los autores de este ensayo - texto que contiene pensamientos que recuerdan claramente a Schelling y Hölderlin, de modo que aún hoy no se puede considerar segura la autoría de $\mathrm{Hegel}^{3}$, en cuya letra se ha transmitido el fragmento - se concentran en el desarrollo de una identidad entre ciencia y arte que culmina en la poesía.

"El filósofo debe tener tanto poder estético como el poeta. [...] La poesía adquiere así una mayor dignidad, y al final se convierte en lo que fue en el principio: maestra de la humanidad; pues ya no hay filosofía, ni historia; sólo la poesía sobrevivirá a todas las demás ciencias y artes"4.

La nueva mitología de la razón requiere un poder estético en el tratamiento de ideas. No se trata de una mitología racional en el sentido habitual de término, es decir, una explicación racional de las imágenes o la relación inequívoca entre concepto e imagen. Más bien, la idea de tal mitología nace de la concepción de que las imágenes pueden representar un concepto en sus referencias y significados de manera más compleja y precisa que una palabra. Por cierto, que las imágenes no responden necesariamente a aquello, por lo cual, surge la pregunta de cómo se pueden crear imágenes mitológicas de esta calidad, en resumen, cómo se puede romantizar el mundo. Sin duda, la idea de una nueva mitología

\footnotetext{
2 M. FRANK, G. KURZ (hgs.), Materialien zu Schellings philosophischen Anfängen, Suhrkamp: Frankfurt am Main, I975, pp.IIO-II2, IIIss: "Zuerst werde ich hier von einer Idee sprechen, die, soviel ich weiß, noch in keines Menschen Sinn gekommen ist - wir müssen eine neue Mythologie haben, diese Mythologie aber muß im Dienste der Ideen stehen, sie muß eine Mythologie der Vernunft werden".

3 Cf. C. JAMME y H. SCHNEIDER (hgs.), Mythologie der Vernunft. Hegels ältestes Systemprogramm des deutschen Idealismus, Suhrkamp: Frankfurt am Main, 1988. F.-P. HANSEN, Das älteste Systemprogramm des deutschen Idealismus. Rezeptionsfeschichte und Interpretation, Walter de Gruyter: Berlin, 1989.

4 M. FRANK, G. KURZ (hgs.), Materialien zu Schellings..., p. III: "Der Philosoph muß ebensoviel ästhetische Kraft besitzen als der Dichter. [...] Die Poesie bekommt dadurch eine höhere Würde, sie wird am Ende wieder, was sie am Anfang war - Lehrerin der Menschheit; denn es gibt keine Philosophie, keine Geschichte mehr, die Dichtkunst allein wird alle übrigen Wissenschaften und Künste überleben".
} 
ha desencadenado un pensamiento que tiene influencias hasta el día de hoy para determinar la relación entre mito y metafísica.

Sin embargo, la supuesta originalidad de una "mitología de la razón" no es tan válida como el joven escritor o los escritores se inclinan a suponer. Sin querer presentar al único inventor de tal pensamiento en este punto, se mostrará a continuación que, en la obra de Nicolás de Cusa, ya hay planteamientos que utilizan el poder estético de la razón para formar una nueva mitología. Sobre la base de la nueva concepción del arte del siglo XV, también en ellos se trata de determinar la relación entre mito y metafísica, que, en gran medida, se piensa desde el sujeto humano, sin que por ello se convierta la metafísica en un objeto puramente racional. La tesis de la presente contribución, que debe mucho al pensamiento de Kazuhiko Yamaki', apunta al hecho de que, metodológicamente hablando, los aenigmas del Cusano ${ }^{6}$ mantienen esta posición de "sistema", lo cual revela una nueva conexión entre el arte, el mito y la metafísica, que Nicolás reflejó en su concepto de una scientia aenigmatica ${ }^{7}$.

\section{El espejo vivo de Dios}

El título de este trabajo hace referencia a una variante de la conocida sentencia italiana: "todo pintor se pinta a sí mismo". Ahora bien, esta variante, que no es el pintor sino el cuadro que se pinta a sí mismo, necesita una explicación ${ }^{8}$.

Para Nicolás de Cusa es fundamental su antropología9. Unas décadas antes de la famosa Oratio de dignitate hominis ${ }^{\text {10 }}$ de Giovanni Pico

5 Cf. K. YAMAKI, Anregung und Übung. Zur Laienphilosophie des Nikolaus von Kues, Aschendörf: Münster, 20I7, donde se encuentran más ensayos en los que K. Yamaki trabaja con el método cusano, trasladando una imagen internamente puesta en movimiento y, desde ahí, muestra perspectivas sorprendentes.

6 Acerca de los aenigmata matemáticos, ver el trabajo fundamental de C. RUSCONI, El uso simbólico de figuras matemáticas en la metafísica de Nicolás de Cusa (I4OI-I464), Biblos: Buenos Aires, 2012.

7 También desde el lado del arte se podría mantener la tesis. Para reflexiones que apoyan esto ver: V. ROSEN, "Res et signa. Formen der Ambiguität in der Malerei des Cinquecento" en I. BOCKEN, T. BORSCHE, Kan das denken malen, Wilhelm Fink: München, 20I0, pp. 243-274.

8 Sobre las implicaciones teológicas, especialmente respecto a la pintura de Klee y Malewitsch, ver: V. RÜHLE, "Der Blick des Bildes und das geistige Sehen" en I. BOCKEN, T. BORSCHE, Kann das Kan das denken malen, Wilhelm Fink: München, 2010, pp. 19-44.

9 Cf. K. REINHARDT, "Anthropologie im Umbrich von Mittelalter zur Neuzeit. Der Mensch als Schöpfer und Geschöpf bei Nikolaus von Kues" en H. SCHWAETZER, H. STAHL-SCHWAETZER (hgs.), L' homme machine? Antropologie im Umbruch. Ein interdisziplinäres Symposion, Philosophische Texte und Studien (45), G. Olms Verlag: Hildesheim, 1998, pp. 219-228.

Io Cf. H. SCHWAETZER, “'Semen Universale'. Die Anthropologie bei Nikolaus von Kues und 
della Mirandola, inspirada por el Cusano, Nicolás esbozó una imagen del hombre que inicialmente parece apoyarse en la teología clásica al retomar el topos bíblico del hombre como imago dei. Es cierto que se puede suponer, para un buen conocedor de Agustín, que tal enfoque no es ingenuo. De hecho, la principal línea de desarrollo de esta antropología radica en la recepción del pensamiento agustiniano y su posterior desarrollo por parte de Meister Eckhart, como ha demostrado Johann Kreuzer ${ }^{\text {II }}$. Siguiendo la sentencia platónica ${ }^{12}$, la línea de tradición mencionada se refiere a la cuestión de cómo el hombre puede asemejarse a Dios ${ }^{13}$.

En el centro de esta corriente, atribuida al neoplatonismo, no está la cuestión si el hombre es semejante a Dios, más bien, si y cómo puede llegar a ser como Dios. Más adelante, desde Agustín, este proceso de devenir se asocia a menudo con la metáfora del espejo ${ }^{14}$ (igualmente platónica). Es en este contexto que Nicolás de Cusa, en su opúsculo De filiatione Dei, discute el reproche de panteísmo que llevó a juicio a Eckhart. Para mostrar que el maestro no identificó de ninguna manera al creador y a la criatura entre sí, el Cusano esboza su pensamiento-imagen del aenigma-espejo ${ }^{15}$.

En ella Nicolás desarrolla por primera vez la idea más importante de su antropología, a saber, que el hombre es viva imago $D e i^{16}$. En ella se describe el siguiente escenario: Hay un único y perfecto espejo: el Logos.

G.Pico della Mirandola" en I. BOCKEN, H. SCHWAETZER, Spiegel und Porträt. Zur Bedeutung zweier zentraler Bilder im Werk des Nikolaus von Kues, Shaker Publishing B.V.: Maastricht, 2005, pp. II3-I32.

II Cf. J. KREUZER, "Der Geist als lebendiger Spiegel. Zur Theorie des Intellekts bei Meister Eckhart und Nikolaus von Kues" en H. SCHWAETZER, G. STEER, Meister Eckhart und Nikolaus von Kues, Meister- Eckhart-Jahrbuch 4 (20II), pp. 49-66; I. MANDRELLA, "Das Subjekt bei Nicolaus Cusanus: Freie und Intellektuelle Natur" en H. SCHWAETZER, M. VANNIER, Zum Subjektbegriff bei Meister Eckhart und Nikolaus von Kues, Aschendorff: Münster, 20II, pp. 77-88.

I2 Cf. PLATÓN, Teeteto I76a: homoiosis theo kata to dynaton.

I3 Cf. I. MANDRELLA, "Intellektuelle Selbsterkenntnis als Anähnlichung an Gott bei Meister Eckhart und Nicolaus Cusanus" en H. SCHWAETZER, G. STEER, Meister Eckhart und Nikolaus von Kues..., pp. 67-82.

I4 Cf. H. Schwaetzer, "Miroir" en M.-A VANNIER, W. A. EULER, K. REINHHARDT, H. SCHWAETZER (Hgs.), Encyclopédie des mystiques Rhénans d'Eckhart à Nicolas de Cues et leur réception, Editions du Cerf: Paris, 20II, pp. 813-820.

I5 Sobre el motivo del espejo en Nicolás de Cusa en términos generales ver: I. MANDRELLA, "Das Spiegelmotiv in der Philosophie des Nicolaus Cusanus", en E. FILIPPI, H. SCHWAETZER, Spiegel der Seele, Aschendorff: Münster, 20I2, pp. I39-I50; S. GROTZ, "Der Spiegel als Gleichnis. Über den Einsatz einer Metapher bei Nicolaus Cusanus" en E. FILIPPI, H. SCHWAETZER, Spiegel der Seele..., pp. I29-138.

I6 Sobre este topos central de la filosofía cusana ver la primera monografía presentada por I. MANDRELLA, Viva imago. Die praktische Philosophie des Nicolaus Cusanus, Buchreihe der CusanusGesellschaft, Aschendorff: Münster, 20 II. 
En tanto única imagen, él es la imagen perfecta de la unidad. Él refleja al Padre divino y, por lo tanto, refleja al mundo perfectamente y sin mancha alguna. Alrededor de este espejo perfecto, hay otros espejos en círculo, espejos imperfectos que están curvados, distorsionados, opacos. Estos espejos reflejan el único espejo perfecto central y, a su vez, simbolizan a las criaturas. Pero entre ellos hay dos tipos diferentes. La diferencia entre ellos es que algunos de ellos están indistintamente distorsionados, mientras que otros tienen la cualidad especial de poder enderezarse y purificarse a sí mismos. Esta auto-referencia asegura su libertad. Finalmente, los espejos de esta especie simbolizan al ser humano.

En cuanto a la cuestión del panteísmo, el Cusano distingue así con mucha precisión entre el único espejo central y los espejos externos. Incluso un espejo exterior perfecto no es el único espejo de la verdad en el medio. Mucho más interesante para el contexto que nos ocupa, sin embargo, es la dinámica del espejo humano. La idea de que el espejo humano puede enderezarse y purificarse en libertad, de modo que a su vez refleje perfectamente el espejo central del Logos, tiene como consecuencia que se da una filiatio Dei para el ser humano, la cual preserva, para la igualdad absoluta, la diferencia entre el ser humano y el único Logos. Al mismo tiempo, sin embargo, la imagen no debe ser pensada como si estuviera un proceso constante de perfección. Esto es así, porque las cosas rectas también pueden volver a torcerse, y lo que ha sido purificado puede cegarse. Más bien, puede suceder que una persona en un momento se vuelva más perfecta o imperfecta.

Nicolás concibe esta antropología en el concepto de viva imago Dei. El añadido que el hombre no es sólo una imagen, sino una imagen viva de Dios pone de manifiesto, con nitidez, una dinámica constante. El hombre es un ser puramente procesual. Siempre se encuentra sólo en "muerte y devenir" (Goethe), ha llegado a un estado que siempre debe ser superado. Este punto de vista tiene dos consecuencias esenciales, una para la antropología y otra para la epistemología.

\section{"Cada cuadro se pinta a sí mismo"}

En cuanto a la antropología, es de gran importancia que Nicolás de Cusa retoma esta sentencia en sus Opuscula escritos alrededor de I445 y desarrolla aún más en 1450 en el escrito De mente. En Roma durante los meses de verano el Cusano escribió sus famosos Diálogos del Idiota, a los que pertenecen: Idiota de Sapientia, Idiota de mente, y el Idiota de staticis experimentis. Antes de discutir las cuestiones de contenido, consideraré 
brevemente las circunstancias históricas.

El hecho de que Nicolás sostuviera un intenso intercambio con los pintores flamencos, es algo que, para el estado actual de la investigación, no requiere mayor discusión ${ }^{17}$. Sumado a esto, es bien sabido que el Cusano llama a Rogier van Weyden pictor maximus en De visione Dei del I $453^{18}$. Está documentado asimismo que Nicolás de Cusa hizo un desvío a Bruselas en su viaje de legación de los años I45I y I452 con el objetivo de ver la obra La Justicia de Trajano y Herkinbald de Rogier van der Weyden en el ayuntamiento de esa ciudad. Ahora bien, si nos preguntamos por el sorprendente interés que Nicolás muestra en Rogier y nos remitimos al verano del año I450, tenemos que coincidentemente es el mismo verano en que creó los Diálogos del Idiota. En el verano de I450 Rogier y Nicolás están en Italia, por lo cual es probable, considerando todos estos antecedentes, que se conocieran en esa ocasión ${ }^{19}$.

Si se quiere acotar aún más el período del verano de la estancia de Rogier van der Weyden en Roma y sus alrededores, éste debió programarse presumiblemente para agosto; van der Weyden viajó, al parecer, de Florencia a Nápoles ${ }^{20}$ durante este período. Nicolás de Cusa completa el 23 de agosto de 1450 el De mente. Él escribe el diálogo - como los otros diálogos idiotas - muy rápidamente y casi de una sola vez. El libro primero de De sapientia se completa el i5 de julio; el segundo, se completa el 8 de agosto ${ }^{21}$. Según esto, el De mente se escribe entre el 8 y el 23 de agosto de I450, es decir, exactamente en el momento en que se da su probable encuentro con Rogier.

Después de esta breve observación preliminar sobre el contexto de los Diálogos del Idiota, veamos ahora un texto central en el que Cusanus explica su antropología. De nuevo es una imagen. Esta vez es una imagen de una imagen. Nicolás combina la metáfora teológica de la imago con la

\footnotetext{
I7 Ver trabajos como: W. C. SCHNEIDER, H. SCHWAETZER, M. DE MEY, I. BOCKEN (hgs.) "Videre et videri coincidunt". Theorien des Sehens in der ersten Häfte des I5. Jahrhunderts, Aschendorff: Münster, 20II. E. FILIPPI, H. SCHWAETZER, Spiegel der Seele.... Los importantes trabajos de H. BELTING, especialmente: Spiegel der Welt. Die Erfindung des Gemäldes in den Niederlanden, Beck C. H.: München, 20IO.

I8 Cf. NICOLÁS DE CUSA, De visione Dei, Praefatio (h. VI, n. 2). Las obras cusanas se citan de acuerdo a la edición crítica, donde h: Nicolai de Cusa, Opera Omnia, Iussu et Auctoritate Academiae Litterarum Heidelbergensis, Leipzig, 1932 ss., indicando en cada caso el volumen y número de parágrafo.

I9 Cf. H. SCHWAETZER, "Das lebendige Selbstporträt bei Nikolaus von Kues und Rogier van der Weyden" en H. SCHWAETZER, E. FILIPPI, Spiegel der Seele..., pp. I6I-I76.

20 Cf. L. CASTELFRANCHI VEGAS, Italien und Flandern. Die Geburt der Renaissance, Belser: Zürich, 1984 .

2I Ver en este punto el Praefatio en h.2V, p. X.
} 
de la pintura. Se dice que:

"Como si un pintor hiciera dos imágenes de las cuales una, sin vida, pareciera en acto más semejante a él, la otra, menos semejante, viva, es decir, tal que pueda siempre hacerse más conforme a sí misma incitada el movimiento por su objeto. Nadie duda que la segunda es más perfecta, como si estuviese imitando más el arte del pintor"22.

Lo propuesto por Nicolás aquí es bastante inusual para el año I450. Él describe el proceso de creación de un autorretrato y, como sabemos, la idea de un autorretrato alrededor del 1450 es, por cierto, bastante moderna. Por lo menos, no tenemos evidencia de algún autorretrato firmado de esa época ${ }^{23}$. Por supuesto, se puede especular sobre tales imágenes de Van Eyck. Sin embargo, en el pasaje citado más arriba se refleja el proceso de pintar un autorretrato. Y no sólo eso, la imagen se moviliza de tal manera que el Cusano sugiere que el cuadro sigue pintándose a sí mismo en el lienzo, independientemente de su pintor y creador. Así, se le confiere al cuadro una independencia de la esencia, toda vez que es el cuadro el que gana la libertad de la independencia.

Diez años más tarde, el Cusano es todavía consciente de la audacia del cuadro. Así escribe en su carta a Nicolás de Bolonia en el mismo contexto de su antropología:

"Si un pintor pinta un cuadro visible de sí mismo, permanece como está hecho; pero si fuera tal pintor, que pudiera hacer un cuadro espiritual e invisible de su arte espiritual de pintar, tal cuadro de su arte, si fuera un cuadro perfecto de arte espiritual y viviente, ciertamente podría hacerse más ligero y más similar, porque sería como su creador"24.

Los aspectos teológicos de esta concepción no serán más tratados aquí ${ }^{25}$, ni se abordarán las implicaciones histórico-artísticas; en otros

22 NICOLÁS DE CUSA, De mente, cap.I3 (h. V², n. I49): “[...] quasi si pictor duas imagines faceret, quarum una mortua videretur actu sibi similior, alia autem minus similis viva, scilicet talis, quae se ipsam ex obiecto eius ad motum incitata conformiorem semper facere posset, nemo haesitat secundam perfectiorem quasi artem pictoris magis imitantem". NICOLÂS DE CUSA, Un ignorante discurre acerca de la mente, J. M. MACHETTA (trad.), Biblos: Buenos Aires, 2005, p. I35. Para un contexto acerca de lo que aquí se llama ars ver: H. SCHWAETZER, "Miroir" en Encyclopédie....

23 Cf. N. SCHNEIDER, Porträtmalerei. Hauptwerke europäischer Bildniskunst I420-I670, Taschen Verlag: Köln, I999.

24 NICOLÁS DE CUSA, Epist. n.8 (ed. v. Bredow).

25 Cf. A. EISENKOPF, "Das Bild des Bildes" en I. BOCKEN, H. SCHWAETZER, Spiegel und Porträt. Zur Bedeutung..., 49-73. 
lugares he sostenido que esta metáfora debe entenderse como una discusión con el óleo sobre tabla de Rogier van der Weyden llamado "San Lucas dibujando a la Virgen"26. Pero incluso sin la referencia al pictor maximus, es claro que esta nueva antropología está profundamente relacionada con la nueva pintura flamenca. El autorretrato y la idea de que el hombre es imagen viva de Dios se funden, en el espacio del arte y la filosofía, en una primera concepción moderna del pensamiento creativo.

Esta inclusión del arte en la antropología tiene consecuencias para la epistemología y la metafísica. La esencia del hombre no se encuentra en la comprensión abstracta, sino en la pintura intelectual y viva de sí mismo. Sin embargo, visto sistemáticamente, una pintura intelectual está relacionada con el mito.

\section{Conjeturas}

Para aclarar la relación entre el mito y la imagen en el Cusano, hay que observar detenidamente la teoría del conocimiento. La procesualidad de una constante recreación de sí mismo, que llega a la humanidad de esta manera, no puede simplemente tomar la verdad como dada en el sentido epistemológico, sino que el concepto de verdad debe ser visto desde el aspecto del desarrollo, sin caer, por cierto, en la arbitrariedad. Nicolás se dedica a la solución de este problema en su segunda obra filosófica principal titulada De coniecturis. Con la noción de coniectura formula su enfoque. Una coniectura se define como la participación en la verdad en la alteridad ${ }^{27}$. La coniectura es, en pocas palabras, una perspectiva de la verdad $^{28}$. No tiene validez absoluta ni es meramente relativa. El Cusano considera el punto de vista subjetivo de la cognición, sin siquiera deducir la subjetividad de la cognición de aquella subjetividad. Uno mira desde una cierta posición en el espacio y el tiempo, por elegir un ejemplo de la sensibilidad. Si emite el juicio, a la vista de una flor florecida: "Esto es una rosa", no significa que la rosa se alcance en su totalidad; porque la rosa que crece y la rosa que perece también le pertenecen. Sin embargo, el juicio no está equivocado. No define lo que es una rosa, sino que la caracteriza bajo una forma de apariencia que es expresión de una ley orgánica de desarrollo.

26 Sobre este tema ver: H. SCHWAETZER, "Das lebendige Selbstporträt...”, I6Iss.

27 Cf. NICOLÁS DE CUSA, De coniecturis I, c. II (h. II, n. 57): "Coniectura igitur est positiva assertio, in alteritate veritatem, uti est, participans".

28 Para comprender este principio cusano resulta fundamental el estudio de I. BOCKEN, Kunst des Sammelns. Philosphie der konjekturalen Interaktion nach Nicolaus Cusanus, Aschendorff: Münster, 2013. 
Para el Cusano lo anterior no es cierto solamente para las rosas y los objetos sensibles en general, sino también para las ideas y para el propio ser humano. Pues incluso los conceptos e ideas aparecen en la mente humana en forma de concepciones subjetivas que sólo ofrecen perspectivas. Aquí es donde comienza la cuestión de una mitología de la razón, y este es el lugar sistemático del arte en la doctrina metafísica del conocimiento, ya que el principio de la conjetura también vale para la visión intelectual ${ }^{29}$, la visio intellectualis. La mente humana siempre puede entender los conceptos de mejor manera. Con todo, se puede preguntar, ¿cómo se entiende un concepto? La respuesta es tan simple como trascendental: en la medida que se le pinta ${ }^{30}$. Con todo, no solo desde esta respuesta se hace comprensible el intenso diálogo entre filosofía y pintura.

Entonces, ¿qué significa pintar un concepto, es decir, formar una representación adecuada del concepto? Evidentemente, también se debe mirar desde tantas perspectivas como sea posible, de manera que la pregunta sea más precisa, a saber, ¿cómo capta la mente humana un concepto en diversas perspectivas que coexisten en la representación? De esto se puede concluir inmediatamente que el Cusano no se preocupa tanto por la imagen acabada del concepto, cuanto por el proceso de pintarlo, cuestión ya sugerida en los pasajes que hemos comentado acerca de la imagen que se pinta a sí misma.

Si se parte del conocimiento sensible tenemos, entonces, que éste se basa en una percepción. Ahora bien, tal percepción es como tal y sólo en sí misma confusa, necesitada de interpretación, cuestión que enseña Nicolás de acuerdo con la más tardía tradición europea, desde el Teeteto de Platón. Es el concepto, la idea, lo que ordena la percepción y, por lo tanto, lo que genera la comprensión. Si se escucha el idioma romano sin dominarlo, como en el ejemplo ofrecido por Nicolás, entonces la percepción no conduce a un conocimiento adecuado ${ }^{31}$.

No obstante, en el mismo lugar Nicolás pone la atención en que quien ve directamente el contenido espiritual ${ }^{32}$, no necesita el equivalente sensorial. De esta manera se remite a otra forma de conocimiento: la

\footnotetext{
29 Cf. H. SCHWAETZER, "Die methodische Begründung der cusanischen Symbolphilosphie. Zum systematischen Verhältnis von imaginatio und visio" en J. M. ANDRÉ, G. KRIEGER, H. SCHWAETZER, Intellectus und Imaginatio. Aspekte geistiger und sinnlicher Erkenntnis bei Nicolaus Cusanus, B.R. Grüner Publishing Company: Amsterdam/Philadelphia, 2006, pp. 83-96.

30 Cf. I. BOCKEN, T. BORSCHE, Kann das Denken....

3I Cf. NICOLÁS DE CUSA, De coniecturis I, cap. I6 (h. III, n. 6o).

32 En el sentido del contenido de la mens. (Nota del traductor).
} 
visión pura (visio) de las ideas o conceptos, como ocurre por ejemplo en el caso de los ángeles. Porque aquello que la visio alcanza con estos, coincide con lo que la visión en último término interpreta. Pero puesto que el hombre, como ser corporal terrestre, no es un ser espiritual puro, la visión de las ideas en él se da primeramente solo en el modo de la imaginación, pero es ahí donde se produce. Es por esto que Nicolás llama a la visión de las ideas una visión no-cognoscente ${ }^{33}$. Por este motivo lo caracteriza como un caso especial en contraposición al conocimiento común; ya que como objeto de la percepción, en tanto necesitado ser interpretado a través del concepto, aparece en la representación del concepto en el cual se interpreta.

Nicolás aclara esta consideración abstracta en De beryllo, usando el ejemplo del ángulo matemático ${ }^{34}$. Según sugiere el Cusano, la mente primero realiza la representación de un ángulo concreto; esto significa que no tiene el concepto de ángulo en su imaginación, sino solo un único ángulo concreto. Ahora bien, la conciencia no imagina simplemente "este ángulo", sino que lo pone en movimiento ${ }^{35}$, para ver imaginativamente las diferentes posibilidades de los ángulos: obtuso, agudo, ángulo recto, etc. Mientras una de las semirrectas del ángulo (o ambas) circula alrededor del vértice, la imaginación recorre por diferentes ángulos. A pesar del movimiento, permanece lo que se ve inicialmente, es decir, no otra cosa que un ángulo concreto, sin embargo, se da un caso de cambio de perspectivas en un continuo movimiento de la imaginación.

Sin embargo, poner en movimiento un ángulo según la imaginación ${ }^{36}$, presupone que se tiene un concepto de él. Pues de lo

33 Cf. NICOLÁS DE CUSA, Compendium cap. I (h. XI/3, n. 2). La negación del conocimiento, acá se entiende en el sentido de ser un modo de visión intuitivo previo al conocimiento (nota del traductor).

34 Sobre esto ver: C. D’AMICO, "Die Rolle der geometrischen Figur in der Zusammensetzung der scientia aenigmatica", en Mitteilungen und Forschungsbeiträge der Cusanus-Gesellschaft 29 (2005), pp. 265-278, pp. 274ss., en las reflexiones en torno a la similitudo; C. RUSCONI, El uso simbólico de las figuras matemáticas..., pp. 222ss. y 233ss.

35 Que las imágenes cusanas, especialmente las matemáticas, sean concebidas como imágenes en movimiento es una cuestión que han mostrado de diversa manera algunos estudiosos, por ejemplo: L. BERMANS, "Nicholas of Cusa's vanishing geometrical figures and the mystical tradition of "Entbildung"” en VV.AA. Das Mathematikverständnis des Nikolaus von Kues. Mathematische, Naturwissenschaftliche und Philosophisch-theologische Dimentionen, Mitteilungen und Forschungsbeiträge der Cusanus-Gesellschaft 29 (2005), Paulinus: Trier, 2005, pp. 313-322. Del mismo volumen: J-M. NICOLLE, “How to look at the Cusanus' geometrical figures?”, pp. 279294; K. YAMAKI, "Die Bedeutung geometrischer Symbole für das Denken des Nicolaus Cusanus. Eine Untersuchung am Beispiel der Metamorphose seiner Auffassung vom Kreis”, pp. 295-3I2.

36 Se entiende aquí el término cusano imaginatio, el cual tiene una significación técnica, en alemán se traduce como "Vorstellung". Para la teoría de la imaginación en Nicolás de Cusa y su relación con la noción de visio ver: H. SCHWAETZER, "Die methodische Begründung der Cusanischen Symbolphilosphie. Zum sistemastische Verhälnis von imaginatio und visio" en J.-M. 
contrario, no se sabría cómo sería mover la estructura sin superar sus propias leyes. En este caso, el movimiento debe tener lugar de tal manera que el vértice del ángulo permanezca intacto y las semirectas no se doblen. Así, al moverse como se mueve, la conciencia ve que en todo movimiento se conservan los elementos decisivos de lo que es un ángulo. Por lo tanto, ve algo diferente en el ángulo imaginado en movimiento. La conciencia todavía ve un ángulo concreto y sensible en la imaginación, pero en este ángulo concreto los constitutivos de lo que es un ángulo, ahora se hacen visibles apareciendo como "constantes en movimiento" en la imagen constantemente cambiante de los ángulos concretos. Cada uno de los ángulos se ve no sólo como "este" ángulo concreto en la imaginación, sino también como un ejemplo de la regularidad de los ángulos.

Esta consideración podría llevarse más lejos en términos epistemológicos ${ }^{37}$. Hasta aquí ya introdujimos suficientemente la idea de una visio intellectualis como una pintura, la cual estando en constante movimiento, es la ejecución de su propia regularidad. El concepto no muestra nada más que a sí mismo cuando llega a ser pensado; y él no puede mostrar otra cosa, pues entonces no sería él.

\section{Scientia aenigmatica: mito y metafísica}

Con el trasfondo epistemológico que hemos mostrado, ha quedado claro que el pasaje de la Primera Epístola a los Corintios (I3,I2): Videmus nunc per speculum in aenigmate tiene un significado especial también para el Cusano, como lo tuvo para Agustín. El espejo que se forma a sí mismo, que se pinta a sí mismo como una imagen, es el ser vivo enigmático. La creación de símbolos espirituales se convierte así en la forma actual del conocimiento y la forma de vida del ser humano. Nicolás llama a esta forma metafísica de conocimiento una scientia aenigmatica.

"El hombre tiene un intelecto que es una imagen similar del intelecto divino en la creación. Por lo tanto, crea imágenes de similitud de las imágenes [sc. ideas] del intelecto divino, así como las figuras artificiales externas son imágenes de similitud de las imágenes de las ideas internas. Por lo tanto, mide su intelecto por la habilidad de sus obras. Y por lo tanto mide el intelecto divino como la verdad es medida por la imagen. Esta es la ciencia enigmática"38.

\footnotetext{
ANDRÉ, G. KRIEGER, H. SCHWAETZER (Hgs.), Intellectus und Imaginatio. Aspekte geistiger und sinnlicher Erkenntnis bei Nicolaus Cusanus, Bochumer Studien zur Philosphie 44 (2006), pp. 83-95. 37 Cf. H. SCHWAETZER, "Ineinsfall der Begegnung", Coincidentia I (2010), pp. 13-38, I9ss.

38 NICOLÁS DE CUSA, De beryllo (h. XI/I, n. 7): "Homo habet intellectum, qui est similitudo
} 
En este pasaje, el Cusano formula la pretensión de que la verdad es medida a través de la imagen y que el intelecto divino lo es por medio del intelecto humano, y no viceversa. Estos dos aspectos son, por supuesto, solo dos lados del mismo proceso. Mientras el intelecto humano realiza su actividad, crea imágenes espirituales. En ellas surgen, a través de ellas genera, aquellos conceptos que también constituyen el intelecto divino. El texto juega con los tres significados de similitudo. En primer lugar, similitudo es el término paralelo a imago presente en el relato bíblico de la creación; que aparece en el pasaje citado más arriba. Por lo tanto, similitudo es el hombre como una imagen de Dios. En segundo lugar, el término ya se usaba en el medioevo para denotar las ideas; uso también presente en el pasaje cusano que nos ocupa. En tercer lugar, el término se entiende tradicionalmente como una imagen o parábola. La frase: veritas mensuratur per imaginem gana su agudeza con esto. Que la verdad se mide por la imagen significa, entonces, que la verdad se mide por el hombre, vale decir, en su actividad intelectual, que es una visión de ideas, porque sólo allí se manifiesta la verdad. Además, la formulación obtiene una mayor fuerza, porque el Cusano en el De mente deriva el vocablo mens desde el término mensurare ${ }^{39}$. Por lo tanto, se puede interpretar esta frase de la siguiente manera: La verdad divina como magnitud metafísica se humaniza a través del proceso pictórico de la actividad intelectual de la imagen de Dios. Por consiguiente, es evidente cómo arte y metafísica están conectados entre sí en el proceso específico de la mens humana.

Una forma de expresión para esto es el aenigma. Gerda von Bredow ha caracterizado acertada y sutilmente lo que son los aenigmata para el Cusano:

"No son conceptos fijos, sino instrucciones para un movimiento de pensamiento, fórmulas para un proceso de pensamiento que no tiene la intención de crear un resultado que se pueda separar de él"40.

\footnotetext{
divini intellectus in creando. Hinc creat similitudines similitudinum divini intellectus, sicut sunt extrinsecae artificiales figurae similitudines intrinsecae naturalis formae. Unde mensurat suum intellectum per potentiam operum suorum et ex hoc mensurat divinum intellectum, sicut veritas mensuratur per imaginem. Et haec est aenigmatica scientia." Ver: C. D’AMICO, "Die Rolle der geometrischen Figur ...", pp. 265-278.

39 En relación a la noción de mensura en el Cusano ver en los trabajos de E. FILIPPI, Umanesimo e misura viva: Dürer tra Cusano e Alberti, Arsenale Editrice: San Giovanni Lupatoto, Verona, 20II; "Ma $\beta$ unf Vermessenheit des Menschen. Cusanus und Dürer als Erzieher" en W. C. SCHNEIDER, H. SCHWAETZER, M. de MEY, I. BOCKEN (hgs.), "Videre et videri coincidunt. Theorie des Sehen in der ersten Häfte des I5. Jahrhunderts..., pp. 333-350.

40 G. von BREDOW, "Gott der Nichtandere" en H. SCHNARR (ed.), Im Gespräch mit Nikolaus von Kues. Gesammelte Aufsätze I948-1993. Aschendorff: Münster 1995, p. 52: "Sie sind keine festen Begriffe, sondern Anweisungen für eine Bewegung des Denkens, Formeln für einen Denkvollzug, der nicht ein von ihm ablösbares Resultat schaffen soll".
} 
El significado habitual de enigma o símbolo no es tan exacto como el término cusano aenigma. Esto debido a que no se trata de una imagen dada, sino a la realización productiva de la creación de una imagen significativa. Una idea es un aenigma precisamente cuando revela en primer lugar una base metafísica de significado, tradicionalmente hablando, una idea que, en segundo lugar, es generada por la propia mente humana y, en tercer lugar, tiene esta cualidad no sólo en términos de contenido sino también en términos de método, es decir, cuando hace la idea vívidamente visible a través de su ejecución. En el sentido de los debates epistemológicos del siglo XIX, la producción es a la vez subjetiva y objetiva. En este sentido, en la scientia aenigmatica cusana, podemos referirnos a la distinción entre validez y génesis del siglo XIX. La validez de una comprensión, según el principio filosófico, surge independientemente de la génesis de tal comprensión. Por ejemplo, para que un estudiante esté en condiciones de comprender el teorema de Pitágoras, debe tener ciertos conocimientos matemáticos básicos. Pero la verdad del teorema de Pitágoras no depende de estas condiciones. Así, mientras que la génesis es generalmente indiferente a la validez, lo inverso no es cierto. La validez tiene un efecto en la génesis y se convierte allí en una capacidad. Quien haya entendido el teorema de Pitágoras, en primer lugar, puede tratar con él y, en segundo lugar, puede entender otras cosas de una manera nueva y mejor. Esta última cualidad de capacidad, sin embargo, sólo se hace visible en la ejecución, como ya enseñó Aristóteles en la discusión del concepto de dynamis ${ }^{41}$. En este sentido, se trata de un acto capacitado y significativo de conocimiento, de una visio de ideas de contenido metafísico en el modo de la representación según imágenes como un proceso artístico-creativo.

El aenigma, entendido como tal proceso, legitima la comprensión de la mens. Para entender la relación entre el aenigma y el mito, este es el punto crucial.

En la discusión de lo que es un ángulo, el Cusano, como hemos visto, no ofrece una definición, sino que inaugura un proceso enigmático. La imaginación en movimiento lleva a una experiencia del surgimiento o manifestación del concepto en el modo de la visión imaginativa. Esta experiencia pictórica es el fundamento de la comprensión de lo que es

\footnotetext{
4I De aquí llega a ser claro, que la génesis es significativa también para la validez, en la medida que ella concierne al portador de la génesis y su autoconocimiento: el individuo humano. La esencia del pintar es el pintar creativo. La imágen es, entonces, semejante al pintor, si él pinta creativamente. No se puede llegar a estar obligado a un ideal dado, sino más bien a su proceso creativo propio e individual. Las consecuencias filosófico-educativas no podrían pasar por alto en este punto.
} 
un ángulo. La imagen dinámica legitima el concepto.

Teniendo esta función a la vista, se hace evidente una relación epistemológica y metafísica entre el aenigma y el mito.

Puesto que el papel del mito y lafilosofía está determinadoen Platón, aunque también ya en los pre-socráticos, por ejemplo en Parménides, en el sentido que el mito es el vínculo entre logos y revelación. En el mito aparece en una forma simbólica propia, que da a los conceptos su propio fundamento.

En la tradición platónica de la Edad Media esta función puede ser bien rastreada. Uno puede leer en este sentido los dos primeros libros de Marciano Capella Las nupcias de Mercurio con Filología; se entenderán de esta manera, además, las obras de Alian de Lille Anticlaudianus y Sobre la lamentación de la naturaleza. Aquellas formas las encontramos también en el Renacimiento. Un conocido ejemplo es el recurso al mito de Narciso al principio del De pictura de Alberti. En el gran metafísico Ficino, el espíritu que ilumina a Diotima en el Banquete de Platón se convierte en el Espíritu Santo ${ }^{42}$.

Considerando la obra del Cusano, es fácil ver que casi todos los conocimientos sistemáticos fundamentales están formulados en forma de aenigmata. Algunos de ellos ya han sido mencionados en este artículo: la metáfora del espejo, la de la propia pintura o el aenigma angular del De beryllo. La lista podría ampliarse con los enigmas matemáticos de De docta ignorantia, la figura $\mathrm{P}$ y la figura U del De coniecturis, la escala del De staticis experimentis, la asamblea de los sabios en De pace fidei, el experimento con el icono en De visione Dei o la imagen del cosmógrafo de Compendium. Finalmente, el juego de las esferas no debería faltar en este recuento.

Para arrojar luz sobre el papel del aenigma, volvamos a uno de los ya discutidos: el del cuadro que se pinta a sí mismo. En un breve esbozo se traza, en lo que sigue, el proceso de introducción del aenigma.

El capítulo I3 de la obra De mente trata sobre el postulado platónico del alma del mundo. La obra escrita en forma de diálogo, permite al idiota, como se nombra al protagonista, desarrollar la tesis de que el proceso de creación se plasma en la imagen del arte. Ya que el arte

42 Cf. FICINO, De amore, Dedicatoria, Blum: Hamburg, 2004, p. 8. 
contiene la sabiduría - él entiende lo que hace, - y la omnipotencia - es capaz de implementarlo, de lo contrario no sería arte - y como tercero necesariamente la conexión entre ambos. En la concepción del idiota, esta conexión no fue familiar para los platónicos. Así ellos pudieron separar al Creador de su creación y asumir un alma propia del mundo. En el trasfondo de las consideraciones cusanas está obviamente, sólo para que se entienda, la encarnación del Verbo de Dios en Jesucristo así como la teoría filosófica de la necessitas complexionis ${ }^{43}$.

En respuesta a estas explicaciones metafísicas abstractas, el orador, interlocutor del idiota, hace una petición: "Le pido que nos ayude de nuevo con un ejemplo" 44 . Este giro de la frase es típico; a menudo se encuentran cosas similares en la transición a un aenigma. Y el procedimiento es siempre el mismo: la obra desarrolla un pensamiento de manera racional-abstracta, y sólo cuando este pensamiento es representado, tal fórmula transitoria conduce a la condensación del pensamiento en una imagen ${ }^{45}$.

Ahora, sin embargo, la imagen no se da simplemente, sino que a su vez se construye dinámicamente. Para dar el ejemplo deseado, el idiota se refiere a la mente humana, que es una imagen del arte divino mencionado anteriormente. Luego retoma el concepto de la imagen en un primer aspecto.

"Por lo tanto, el espíritu es creado por el arte creativo, como si ese arte quisiera crearse a sí mismo, pero, como el arte infinito no puede ser multiplicado, su imagen es creada, como si un pintor quisiera pintarse a sí mismo y, como él mismo no puede ser multiplicado, su imagen es creada cuando se pinta a sí mismo" 46 .

Ahora bien, la introducción del aenigma se dirige primeramente a la relación entre el cuadro y el pintor. Ella sostiene una forma necesaria de conexión entre la mens divina y la mens humana, esto sobre la base que

43 Cf. C. RUSCONI, El uso simbólico de las figuras matemáticas..., pp. 25 ss.

44 NICOLÂS DE CUSA, De mente cap. XIII (h. V, n. I48): "Sed quaeso, ut iterum aliquo exemplo nos iuves".

45 Para mencionar solamente otro ejemplo remito a la obra cusana De possest en el parágrafo n. 8. Sobre esto J. M. MACHETTA, "Nicolás de Cusa: El juego del trompo y las aporías de tiempoeternidad el Trialogus De Possest (I460)" en T. REEGEN, Tempo e eternidade na Idale Média, Est Ediciones: Porto Alegre, 2007, pp. I3I-I36.

46 NICOLÁS DE CUSA, De mente cap. XIII (h. V, n.I48): "Unde mens est creata ab arte creatrice, quasi ars illa se ipsam creare vellet et, quia immultiplicabilis est infinita ars, quod tunc eius surgat imago, sicut si pictor se ipsum depingere vellet et, quia ipse non est multiplicabilis, tunc se depingendo oriretur eius imago". (Traducción del autor) 
el arte divino se crea a sí mismo, crea una imagen suya. Esa imagen es, de un lado, el Logos divino y, de otro, la mens humana. Ese proceso es ilustrado con la idea vanguardista de un autoretrato en la pintura.

En este nivel del aenigma falta, empero, el pensamiento del pintarse a sí mismo de la imagen. Esto se comprende, dado que no es tematizado el pensamiento del arte como arte, es decir, el proceso creativo, referido por sí mismo. En el siguiente paso comienza por este aspecto:

"Y porque la imagen nunca es perfecta en toda forma, dada la condición de que no puede ser más perfecta y más conforme al ejemplar, es de tal manera perfecta como cualquier imperfecta imagen, la cual tiene siempre la potencia para adecuarse más y más sin limitación al ejemplar inaccesible"47.

Como vemos, ahora se concibe la relación entre la imagen y el pintor de tal manera, que la relación del proceso es tenida en cuenta. El arte quiere crearse a sí mismo; sólo puede hacerlo en el cuadro, pero este cuadro, como cuadro, tiene la capacidad creativa de la pintura.

El poder creativo divino ha entrado en la mente humana. Esto describe la encarnación del Logos, y lo hace en un espacio de pensamiento, como Cusanus a menudo lo toma prestado de Meister Eckhart: Cristo atrajo la naturaleza humana en la encarnación. Lo que para Eckhart es un nacimiento místico, es figurado por Cusanus en la imagen contemporánea de un nuevo mito del hombre, nutrido por las fuentes del arte y la metafísica.

A continuación, el texto desarrolla cómo esta imagen se compone igualmente de sabiduría, poder y su combinación, y así el hombre se convierte en un imago viva artis infinitae ${ }^{48}$.

\section{Scientia aenigmatica como una nueva mitología de la razón}

Resumiendo, podemos decir lo siguiente. En el ejemplo desplegado en esta contribución, se muestra claramente cómo Nicolás de Cusa asume el concepto y el significado de la función legitimadora del mito en términos de contenido y método, pero también lo reescribe. En el caso del aenigma de la imagen de pintura que se pinta a sí misma, ambos coinciden. El

47 NICOLÁS DE CUSA, De mente cap. XIII (h. V, n. I49): "Et quia numquam quantumcumque perfecta, si perfectior et conformior ese nequit exemplari, adeo perfecta est sicut quaecumque imperfecta imago, quae potentiam habet se semper plus et plus sine limitatione inaccessibili exemplari conformandi".

48 Cf. NICOLÁS DE CUSA, De mente cap. XIII (h. V, n. I49). 
mito platónico de la creación del alma del mundo es corregido con la figura de la transferencia del arte divino a la imagen de Dios. Este cambio significa metódicamente que el mito ya no recibe su legitimación sólo desde el lado de la revelación, sino que el fundamento epistemológico de aquello se reconoce en la visio conjetural de ideas. La propia mente humana como sujeto crea la mitología que mantiene al mundo unido en su núcleo. Esto se gana, empero, desde la actividad del intelecto como imagen de la actividad intelectual divina. El método unificador es el arte, entendido como un proceso creativo más allá de la dualidad de la subjetividad y la objetividad.

En consecuencia, Nicolás de Cusa esbozó, a principios del Renacimiento, una mitología de la razón como metafísica a partir de la vis creativa del pensamiento humano. Esto va acompañado de la pretensión, que esta actividad es adecuada para medir la realidad espiritual de la verdad divina, en la medida que esta actividad la lleva a una nueva aparición. Este medir asegura al hombre tanto el encuentro como la frontera con Dios y consigo mismo. De esta manera, el concepto de scientia aenigmatica es la expresión de una nueva relación entre el mito y la metafísica en el Renacimiento. 
